\title{
Life Expectancy in Germany Based on the 2011 Census: Was the Healthy Migrant Effect Merely an Artefact?*
}

\author{
Felix zur Nieden, Bettina Sommer
}

\begin{abstract}
The Federal Statistical Office's 2010/12 general life table is the first to provide results on life expectancy based on census data for reunified Germany. This article therefore examines the question of how the revisions of the population figures from the 2011 census affected the measured life expectancy. To do so, we analysed both the official life tables based on the old intercensal population updates before the census and those based on the population data from the 2011 census. The method used to calculate the census-adjusted 2010/12 general life table was also transferred to separate life tables drawn up for the German and the foreign population. In this way, findings on the so-called "healthy migrant effect" can be discussed, ruling out possible errors in the intercensal population updates. These errors had previously been cited as the main causes for a distinctly longer life expectancy among the foreign population compared with the German population. As expected, a census-based calculation for the total population and for the German population resulted in only minor revisions to the life expectancy figures. The use of the census results does, however, distinctly alter the life expectancy of foreign women and men. An advantage of over 5 years in life expectancy at birth, measured on the basis of the old population data, needs to be revised to about 2.9 years for men and 2.1 years for women based on the 2011 census. The healthy migrant effect therefore cannot be traced back solely to data artefacts from the old intercensal population updates - even with revised data, the foreign population shows marked survival advantages.
\end{abstract}

Keywords: Life expectancy $\cdot$ Life table $\cdot$ Mortality $\cdot$ Census effects $\cdot$ Healthy migrant effect

This article contains supplementary material in the form of an online Appendix: DOI 10.12765/ CPoS-2016-06en, URL: http://www.comparativepopulationstudies.de/index.php/CPoS/article/ view/198/226. 


\section{Introduction}

The data from the 2011 census for the first time enabled demographic analyses for post-reunification Germany based on population data as accurate as possible. Since the last censuses in former West and East Germany were conducted in 1987 and 1981, respectively, analyses of reunified Germany's population figures have had to refer to data from the intercensal population updates. These updates were based on the last census in former West Germany and an excerpt from the central registry of East Germany dated 3 October 1990, which were updated upon taking the statistics on births and deaths as well as immigration and emigration for each calendar year into consideration. Inaccuracies in these statistics inevitably lead to inaccuracies in the updated population figures. The quality of the data on births and deaths is considered good, but net migration tends to be too high because not all emigrants register their departures and they therefore are missing in the migration records. As a consequence, the number of residents in Germany was adjusted downwards by about 1.5 million persons following the 2011 census. In addition, changes to the population figures in various demographic categories, such as age, sex or nationality, also have a great impact on demographic analyses. For these dimensions the census was adjusted to varying degrees (Kaus/Mundil-Schwarz 2015: 29-32).

This article explores the effects of the 2011 census on the measurement of life expectancy in Germany, using the data and the approach of the 2010/12 general life table for Germany. A general life table is always drawn up when a census is conducted. In addition, general life tables are smoothed to eliminate random effects in order to use precise population data to reveal fundamental mortality patterns. One special focus of this article is the creation of life tables according to nationality (German/non-German) based on the census data. It was no longer possible to reach plausible results, in particular for the foreign population, based on the data from the intercensal population updates with ever-greater intervals to the previous census. However, reliable data on the mortality of the foreign population is highly relevant, in particular against the background of the rising numbers of this population group. Immigration is frequently discussed as an option for lessening Germany's demographic problems, the anticipated decline in population and demographic aging. Knowledge of the mortality situation of the foreign population helps to better estimate the associated consequences for the social security system, in particular for the pension, health and long-term nursing care insurances. Moreover, reliable life tables broken down by nationality are an initial basis for differentiated projections of the relevant population groups. In addition, mortality parameters such as life expectancy also contribute to describing the "life circumstances" of different population groups. In the relevant academic discourse, reliable results based on the 2011 census enable us to re-evaluate a variety of hypotheses that have been made about the healthy migrant effect for the foreign population in Germany. Since errors in the population updating procedure can be ruled out when using data from the 2011 census, explanatory hypotheses can be discussed without this caveat. Section 2 of this article provides an overview of the relevant state of research. Section 3 contains the research questions derived from this research state and Section 4 describes the 
data and methods employed. The results of the analysis are then presented in Section 5 and discussed in Section 6.

\section{State of research}

The main effects of the 2011 census on the creation of the official life tables and the related consequences for measuring life expectancy have previously been discussed in the special report on the 2010/12 general life table (Statistisches Bundesamt 2015a). It pointed out that life expectancy at birth in Germany based on the census is 0.25 years shorter for males and 0.10 years shorter for females than indicated in calculations based on the old updates. The report also delved into the effects of using census data at the age-specific level. It showed that the age-specific probabilities of death based on the census are consistently higher in contrast to values based on the old population updates.

The most distinct revisions to the probability of death were in those age groups in which adjustments of the population data were most extensive following the census: the ages of 20 to 40 years and at the advanced ages of about 85 and older. Among the very old, the revisions would have been even more pronounced if an extrapolation method had not been used. This method rectified the implausible progressions in the probability of death based on the old updates for age 91 and above (Eisenmenger 2003). The census adjustments were more pronounced in the entire age range among males than females (Statistisches Bundesamt 2015a: 21-23). With regard to census effects for a separate calculation of life tables for the German and foreign populations, until now results were presented using the preliminary intercensal population updates based on the 2011 census for the year 2013. According to this, the difference between non-Germans' and Germans' life expectancy at birth for men drops from 4.8 to 2.6 years, for women a census-adjusted difference of 1.7 years was ascertained in favour of female foreigners (Koh/s 2015: 522).

The age and sex patterns of the population revised after the 2011 census, which in turn lead to revisions of mortality patterns, are described in Kaus/Mundil-Schwarz (2015) as per 31 December 2011. The same article also shows that the revisions among the foreign population were considerably greater than among the German population. With an adjustment factor of 1.9 percent for the total population, the German population was revised by only 0.6 percent, but the foreign population by 14.4 percent. The revisions among the foreign population also involve larger age ranges than among the total population. Also, among the foreign population the male population required far more revisions than the female (Kaus/Mundil-Schwarz 2015: 30).

Even in advance, we anticipated that the census would involve a distinct revision to the foreign population data. One reason for this was the implausible mortality pattern for the foreign population that had been ascertained based on the old population updates. Using the data from the intercensal population updates, researchers consistently discovered pronounced differences in the mortality of non-Germans compared to the German population or the total population in favour of non-Ger- 
man persons. A large part of this effect was explained with data artefacts such as an excessively high foreign population resulting from an population update error or not accounting for deaths abroad (Luy 2007; Kibele et al. 2008; Koh/s 2008a/b, 2011, 2012; Mammey/Schwarz 2002; Robert Koch Institut/Statistisches Bundesamt 2008). As a consequence, various other data sources were used to quantify the mortality of the foreign population in Germany and to show differences to the German or the total population.

Luy (2007), for example, used the data from the Integration Survey by the Federal Institute for Population Research in order to estimate the life expectancy of foreign persons at the age of 35 using an indirect method (the orphanhood method combined with the Brass's logit model). The result showed far lesser mortality differences than those based on the intercensal population updates, however, also this indirect approach results in a lower mortality of the foreign population. Koh/s (2008b, 2011, 2012) reached similar results using data from the Central Register of Foreign Nationals (Aus/änderzentralregister). If life expectancy at birth of the foreign population is measured using the Central Register of Foreign Nationals, the differences to the German population, for example in the year 2009, are about 0.8 (females) to 1.0 years (males) lower than when calculated using the data from the intercensal population updates. Prior to 2005 , more distinct differences were found between the German and foreign populations using the data from the Central Register of Foreign Nationals, which, however, were greatly reduced as a result of a registry revision conducted in the year 2004 (Kohls 2012: 149; Opfermann et al. 2006: 484-485).

Using data from the statutory pension fund (Gesetzliche Rentenversicherung or GRV), Kohls (2008b) also detected the effect of a greater life expectancy in the foreign population with regard to remaining life expectancy at the age of 60 . Although the differences are less pronounced than those based on the population updates, there was still a higher figure for the foreign population compared to the German population. The mortality differences between the German and foreign population dropped drastically between 1994 and 2006 according to the results (Koh/s 2008b: 32-38). In further analyses with GRV data, there was an even higher mortality level among the foreign population over age 60 compared to the German population since 2002 (Koh/s 2008a, 2010, 2011, 2012). Between the ages of 20 and 59, a lower mortality level for the foreign population compared to the German population can be identified using GRV data (Koh/s 2010, 2012). The infant, child and juvenile mortality levels in the foreign population tend to be higher than those of the German population (Koh/s 2011, 2012). In this case, the intercensal population updates are reliable because the biases relevant at higher ages "practically do not exist" for this age group (Koh/s 2008c: 41).

The advantages in the survival conditions of the foreign population are largely ascribed to a so-called healthy migrant effect, which implies that migrating persons are positively selected, i.e. that they are particularly healthy compared to the nonmigrating population and that their mortality is therefore lower. Positing such an effect, however, also suggests that the mortality advantage should decrease over time and can cross over, in particular in the case of socioeconomic disadvantages to 
the foreign population, into a mortality disadvantage (Razum 2009: 268-269; Koh/s 2008c: 17). There are numerous indications of a distinctly lower mortality among migrating persons not only in the national studies for Germany mentioned above, but also in many international studies for other countries (Koh/s 2012: 69-70). For their findings on the healthy migrant effect, most studies compare the health or mortality of the native population with the respective immigrant population. For four major immigration countries (USA, Canada, United Kingdom and Australia), Kennedy and Kidd (2015) show that immigrants also typically exhibit distinct health advantages compared with the natives of their respective countries of origin. We cannot, however, speak of a universal pattern. If we examine self-reported health, multiple European countries' immigrants exhibit poorer health than the respective native population (cf. Nie/sen/Krasnik (2010) for a detailed review of existing studies). Based on harmonized data from health surveys, Moullan and Jusot (2014) find indications of a health advantage among immigrants in Italy, but poorer health among immigrants in France, Belgium and Spain. The authors ascribe these findings to differing selection effects in the immigration and the integration of immigrants. The health advantage of immigrants in Italy is also explained by the fact the natives there exhibit poorer self-assessed health than, for example, in France (Moullan/Jusot 2014: 84).

In the German context, Koh/s $(2011,2012)$ classifies the mortality differences between the German and the foreign population as follows: A mortality advantage in the middle age groups is indubitably verifiable among the foreign population and can be explained by the typical selection effects. The majority of employment-oriented immigrants immigrate between the ages of 25 and 40 . Accordingly, a greater percentage of the foreign population of working age exhibits a comparatively short duration of stay so far, which is why selection effects which are strongest directly following immigration ensure a lower mortality level among the foreign population.

The lesser mortality differences and the higher mortality among the foreign population roughly from age 65 are explained by adaptation effects. Over the course of a longer duration of stay, the level of mortality of the German and foreign population approximate and can, accompanied by given mortality-relevant disadvantages for the foreign population, also change suddenly into a higher mortality among nonGermans. The comparatively high relative mortality risks for the foreign population at the ages of 65 to 69 can, for example, be explained by the large percentage of former guest workers in this age group. They immigrated over the course of the 1950 s to 1970 s and were usually subjected to very strenuous working conditions for decades, which can explain the relatively high mortality of the relevant age group (Koh/s 2012: 181).

The causes for the higher mortality of infants, children and adolescents among the foreign population have so far scarcely been explained in theory. Weber et al. (1990) demonstrated empirically that the higher infant mortality of children of foreign nationality born in Germany is caused primarily by shorter pregnancies compared to German mothers and by an increased occurrence of birth defects and infectious diseases. This could be the consequence of insufficient care given to pregnant female immigrants. Among children and adolescents, Weber et al. (1990) 
identified higher mortality caused by accidents as the chief explanatory factor for the higher overall mortality of the foreign population. For other causes of death, foreign and German children and adolescents exhibit very similar mortality risks. However, using newer data the differences in accident-related mortality between the German and foreign populations of children and adolescents can no longer be identified. Between 1999 and 2004, foreign children and adolescents actually exhibited a somewhat lower accident-related mortality compared to Germans of the same ages. Certain differences between the two groups could only be identified when broken down according to types of accidents (Robert Koch Institut/Statistisches Bundesamt 2008: 71-73).

\section{$3 \quad$ Research questions}

The effects of the census on the creation of the official life tables for the period 2010/12 have already been discussed elsewhere (Statistisches Bundesamt 2015a). The publication focused on the effects of the census on the calculation of the agespecific probability of death. At the level of age-specific life expectancy, the census effect has so far only been quantified for the life expectancy at birth. In this article, we aim to analyze these effects for the entire age-span. Our first research question for this study is therefore:

What effects do the census adjustments of the population have on age-specific life expectancy in Germany and how can these revisions be classified in the context of the annual changes to mortality levels?

We anticipate particularly strong effects from the census adjustments with regard to the creation of life tables for the foreign population. The weaknesses of the official statistics with regard to the analysis of mortality patterns for the foreign population were, in the available publications on the subject, chiefly blamed on population updating errors due to missing notices of departure since the last censuses in former West and East Germany. This article therefore will examine a central second research question:

How great are the mortality differences between the German and foreign population based on the data of the 2011 census, i.e. without the population updating errors?

Methodological aspects are not trivial, in particular when calculating a life table for the foreign population. An extrapolation of the probability of death at an advanced age can have considerable effects on actual measured life expectancy. Therefore, in the context of answering the second research question, we will emphasize the significance of various methodological aspects. For instance, we will clarify up to what age the data from the 2011 census allow us to ascertain plausible patterns in age-specific mortality and what improvements there are in this regard 
compared with the updated data. Hence, the answer to the second research question can inform us at what weight the explanatory factors cited in the literature (selection and adaptation hypotheses) actually contribute to the mortality differences in the German and foreign populations. Should the usually reliable census data demonstrate that the mortality differences between the German and the foreign population approximate greatly with age, this would be a distinct indication in favour of the adaptation hypothesis. If the probability of death of the two population groups differs systematically in favour of the foreign population even at advanced ages, this would speak in favour of the selection hypothesis. If, based on the census data, we ascertain no differences between the German and foreign population, then the differences found so far could be entirely based on inaccuracies in the intercensal population updates, and citing hypotheses to explain the differences would be altogether unnecessary.

\section{$4 \quad$ Data and methods}

\subsection{Data}

All calculations were carried out using the data from the official population statistics according to sex and birth cohort, and deaths according to sex, age and birth cohort. For the population on the census reference date for 2011 we use the initial data from the intercensal population updates. The Federal Statistical Office and the statistical offices of the Länder optimized the calculation of the initial data resulting for the 2011 census for the intercensal population updates, also with regard to the calculation of demographic metrics (Statistisches Bundesamt 2015c). These data and the final intercensal population updates based on them are therefore adequate for mortality calculations. The census data also have numerous advantages compared with alternative data sources for ascertaining mortality among the foreign population, such as the Central Register of Foreign Nationals or the GRV data. Although on principle the aim of the Central Register of Foreign Nationals is also thorough recording of the foreign population, as with the data from the intercensal population updates, adjustments are always necessary since departures in particular cannot all be recorded (Fleischer 1989; Opfermann et al. 2006). The most recent comprehensive adjustment to the Central Register of Foreign Nationals took place in the years 2000 to 2004 , so that at present renewed adjustments are probably necessary. In addition, reports of cases of infant deaths are not mandatory in the Central Register of Foreign Nationals (Koh/s 2012: 148), which impedes the recording of the important component of infant mortality based on this data source. Different recording and reporting channels as well as different definitions with regard to the residencies of foreigners for the Central Register of Foreign Nationals also impede comparisons with the data ascertained in the conventional way for the German population (Opfermann et al. 2006; Kaus/Mundil-Schwarz 2015). Analyses based on the data from the GRV are not representative for the total population since they can only consider actively insured persons and exclude, for example, the self-employed and 
civil servants, and therefore do not constitute a total survey of the population (Koh/s 2008c: 33). Comparability of the results by sex is limited due to the lower numbers of employed females. Infant, child and juvenile mortality can also not be quantified with data from the statutory pension fund, and adult mortality before retirement only with restrictions, which is why no complete life tables can be drawn up based on these data.

\subsection{Methodological considerations}

The analyses in this article are based on the methods used by the Federal Statistical Office to compile the 2010/12 general life table (Statistisches Bundesamt 2015a). The main approach to drawing up the 2010/12 general life table was to calculate the age-specific probability of death with the cohort method according to Becker (1874) and Zeuner (1869) taking the complete census populations into account. The influence of migrations in the period under review was taken into consideration with the aid of the so-called Wittstein-Balducci hypothesis (Wittstein 1862; Balducci 1917). The advantage of this methodological approach is that data from the intercensal population updates do not need to be used to calculate the probability of death for a three-year period, but we can use the more precise population figures of the census. The influence of updating or back-calculation errors - caused, for example, by missing notices of departure in the relevant period - can thus be excluded.

Using the approach of the Federal Statistical Office for the 2010/12 general life table, separate life tables were drawn up for this article according to nationality for the German and the foreign population. It is important to take various methodological aspects into consideration:

The results of a period life table mainly show the mortality conditions of a hypothetical cohort. With regard to life expectancy at birth, period life tables thus answer the question of how long persons of a certain age would live if they were constantly subjected to the survival conditions of the period under review. If we calculate a period life table for subgroups of a total population, we must question whether the measured age-specific probability of death of this subgroup is truly representative for the respective age of the group of persons. For a life table on the foreign population, this means that a large percentage of the population included in the calculation immigrated during the course of their lives and therefore we have no information on the mortality of this group prior to their immigration. Consequently, when drawing up life tables for the foreign population, in addition to the assumption of a hypothetical cohort, another assumption plays a pivotal role: that the (unobserved) mortality prior to immigration is identical to that of the observed domestic mortality of persons of a corresponding age who immigrated at an earlier age or were born with a foreign nationality. For this reason, the (period) life expectancy of the foreign population should be interpreted as the average lifespan of persons who would have been subjected to the survival conditions of the foreign population that prevailed domestically for the duration of the period under review. The mortality conditions prior to immigration cannot be taken into consideration. The necessary additional assumption refers in particular to the life expectancy at birth and the remaining life 
expectancy at a young age. The remaining life expectancy at an advanced age, for example from age 60 , would be less affected by this since migration movements play a lesser role in this age range. The fact that due to changing migration patterns the composition of the foreign population changes far more quickly than that of the German population additionally ensures that the assumption of a hypothetical cohort is more problematic than when drawing up a period life table for the total population (in which the foreign population is only a small percentage) or for the population with German nationality.

Another point that demands consideration is that of the effects of a so-called "unhealthy re-migration effect" (Razum et al. 1998: 302). This is the possible selective remigration (say for treatment purposes) of foreign persons with serious diseases who die abroad (Koh/s 2008c: 21). Deaths among the resident population that occur abroad for other reasons (e.g. while on holiday) can also have a biasing effect if the relevant reports do not reach the statistical offices. The probability of death is then influenced by effects on the numerator (unreported deaths) or the denominator (unreported departures). For the years 2011 and 2012, there are a little over 3,500 known cases of persons with residences in Germany who died abroad per year. ${ }^{1}$ In these years, a little fewer than 1,000 deaths abroad were reported to the German civil registries and could therefore be included in the mortality data. Accordingly, there is still a gap of about 2,500 deaths that occur in Europe outside of Germany every year but are not included in the mortality statistics (or roughly 0.3 percent of all deaths). It is still unknown how many additional deaths occur abroad, for example of persons who are counted both among the population in Germany and in a foreign country.

An additional data-related restriction is that separate life tables for Germans and foreigners cannot take a change of nationality into account. When, for example, a person held a foreign nationality at the time of the census, changed his or her nationality following the census and then died, the death is registered as a death among the German population and is incorporated into the calculation as such. Considering a naturalisation rate of 1.4 to 1.7 percent in the relevant period (Statistisches Bundesamt 2015b) and the fact that most newly naturalised persons survived the period under review, any possible biasing effect would, however, be negligible.

Application of lus soli since the year 2000 (whereby under certain conditions children of foreign parents born in Germany receive German nationality), can also bias a life table calculation separated by nationalities. In particular, biases can occur when infant mortality is calculated directly from the birth statistics if a birth with foreign nationality is registered but a later attainment of German nationality no longer

1 Based on unpublished evaluations by the Federal Statistical Office (Table N30) and the table on "Causes of death - Deaths by country of residence and occurrence" (hlth_cd_aro) in the online database of Eurostat (2015). The Eurostat table identifies "All deaths of residents in or outside their home country." If, from the deaths registered in Germany, we subtract those reported from abroad, we reach the number of domestic deaths. The difference between this figure and the Eurostat figure for all deaths in or outside Germany in 2011 and 2012 was about 3,500 cases each year. Deaths outside Europe are not taken into consideration. 
influences this statistic. Using this example, the death of a German child would be referenced to the wrong population group. This constellation would therefore lead to an underestimation of infant mortality among the foreign population and a (probably marginal) overestimation among the German population. When calculating the probability of death based on the census data there should not be any bias as a result of lus soli in the following age years, since the relevant cases were revised during the census (Kaus/Mundil-Schwarz 2015: 31). If it were calculated based on the updated population data prior to the 2011 census, the effect would be relevant even for the calculation of the probability of death in the following age groups.

In order to smooth the observed age-specific probabilities of death, for the 2010/12 general life table of the Federal Statistical Office a P-spline approach according to Eilers and Marx (1996) was chosen, which, by incorporating the binomial distribution, is especially tailored to smoothing probabilities of death (zur Nieden et al. 2016: 65). Smoothing the probabilities of death is necessary in particular when general patterns need to be derived without random influences or special effects. Such general age-specific patterns are suited, for example, as the basis for a mortality projection, in particular since random influences are not permanently updated and the derivation of future mortality patterns is more plausible. For the calculations of life tables according to nationality conducted additionally for this study, we also smoothed the age-specific probabilities of death using the P-spline method in order to rule out an over-interpretation of random overlaps and restrict ourselves to the analysis of basic patterns.

In order to be able to make statements about age ranges in which the probability of death of Germans and non-Germans significantly differ based on this basic pattern, we additionally calculated confidence intervals for the age-specific probability of death. We assumed that the respective observed age-specific probability of death $q(x)$ is the true expected value and calculated the limits in which random samples would lie with a probability of 95 percent (Salzmann/Koh/s 2006: 187-188).

As with the 2010/12 general life table, we also extrapolated the probability of death at advanced age on the onset of implausible patterns for the additional life tables drawn up for this study. Examples of implausible patterns are overlapping probabilities of death for males and females and/or a distinct flattening or drop in the probability of death. The extrapolation method used here was the logit model that goes back to the work of Perks (1932) and that was assessed as particularly suited for this purpose by Thatcher et al. (1998).

In order to work out the effects of the census, life tables were also compiled with data from the intercensal population updates based on the 1987 census in former West Germany and from the excerpt from the central registry of East Germany dated 3 October 1990 (i.e. the old population updates before the census) (Statistisches Bundesamt 2013). The 2009/11 official life table was also consulted (Statistisches Bundesamt 2012) in order to be able to put the census effect on the 2010/12 general life table in context with the drop in mortality in comparison with the previous life table. For this, we used the differences in the age-specific life expectancy $e(x)$ from the 2009/11 life table and a life table for 2010/12 based on the old updates and based on the census to calculate a mortality effect (ME). 


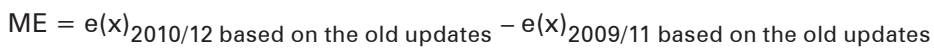

and a census effect (CE)

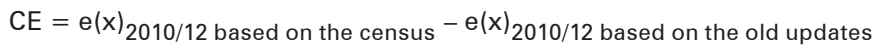

The sum of the two effects reflects the actual change in the age-specific life expectancy between the life table for 2009/11 and the 2010/12 general life table.

In order to work out the differences in the mortality of Germans and non-Germans we calculated a relative measure $\left(U_{x}\right)$, which relates the difference in the agespecific probability of death $\left(q_{x}\right)$ of the two groups to the values for the German population:

$$
\mathrm{U}_{\mathrm{x}}=\frac{\mathrm{q}_{\mathrm{x} \text {, Non-Germans }}-\mathrm{q}_{\mathrm{x} \text {, Germans }}}{\mathrm{q}_{\mathrm{x} \text {, Germans }}}
$$

\section{$5 \quad$ Analyses}

\subsection{Effects of the census on the measurement of mortality among the total population}

According to the 2010/12 general life table, life expectancy at birth in Germany was 77.7 years for men and 82.8 years for women. In comparison to the 2009/11 life table, the figures for life expectancy at birth are therefore unchanged for men and only slightly changed for women (+0.1 years). Figure 1 shows the differences between the 2009/11 life table and the 2010/12 general life table separated according to a census effect, a mortality effect and a combined effect for the entire age course of (remaining) life expectancy. For both men and women, life expectancy at birth and remaining life expectancy until about age 70 would have risen by about 0.2 years compared with the two life tables based on earlier enumerations if no census had been conducted (mortality effect). The drop in mortality and thus the rise in life expectancy would have been somewhat more pronounced for men than for women. For both sexes, the gains in remaining life expectancy decline steadily due to the mortality effect starting at age 70 at the latest and running until age 90 . Above age 90 practically no change is measurable in remaining life expectancy based on the old update data. We must take into account that to calculate the effect from age 91 onwards, figures are compared resulting from the use of an extrapolation model. The drop in the mortality effects observed before age 90 indicates, however, that the lack of a rise in remaining life expectancy above the age of 90 is quite plausible.

The census adjustments made during the compilation of the general life table ensure that the remaining life expectancy in the period 2010/12 for the entire age course of both sexes is shorter than that based on the old updates. The adjustments are far greater among men than among women and drop slightly with increasing age (with the exception of women over the age of 90).

Adding up the mortality effects and the census effects enables us to illustrate the combined effect: the change in age-specific life expectancy between the 2009/11 
Fig. 1: Differences in age-specific life expectancy between the 2009/11 life table and the 2010/12 general life table according to separated effects for men and women

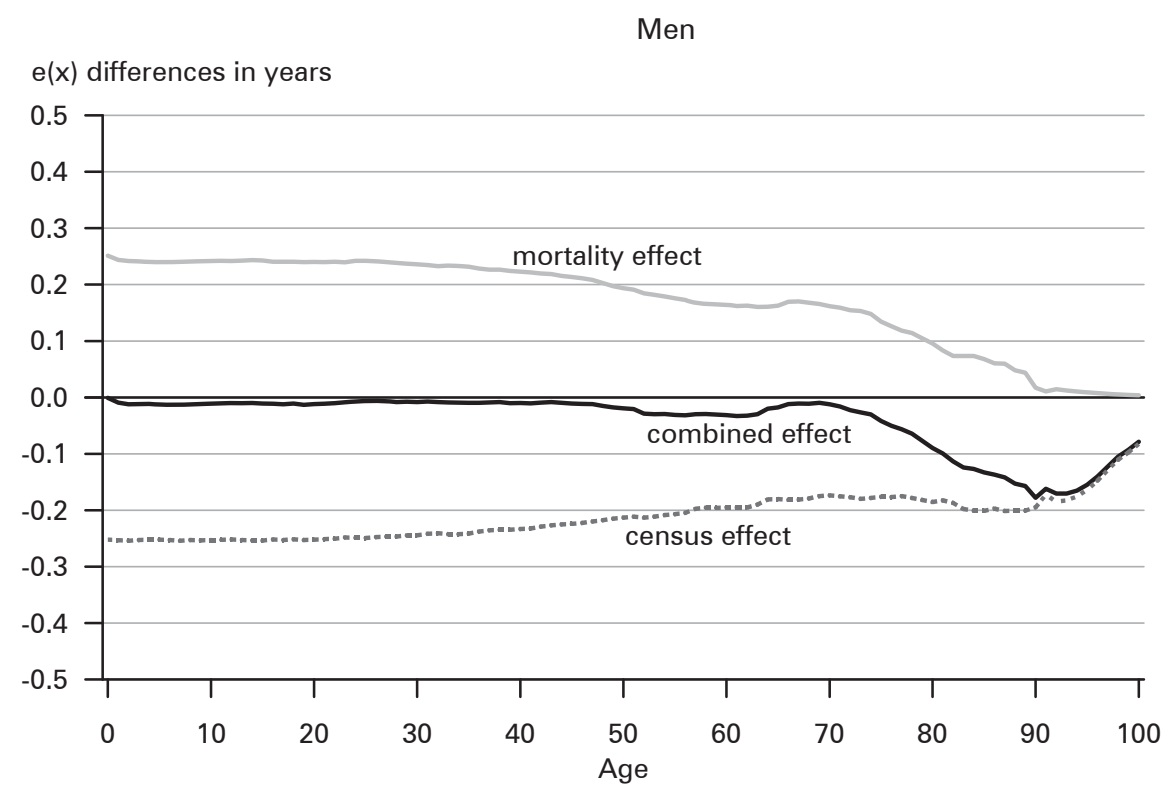

Women

$\mathrm{e}(\mathrm{x})$ differences in years

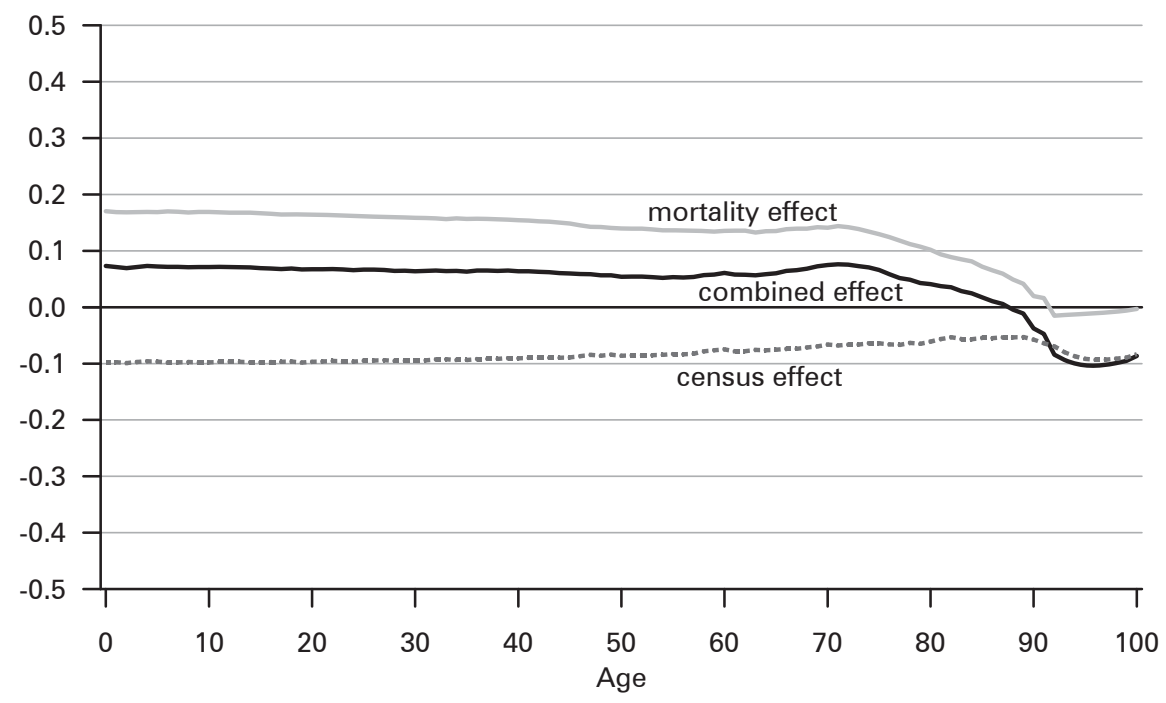

Source: Federal Statistical Office, own calculations and design 
life table and the 2010/12 general life table. For men, the mortality and the census effect almost balance one another out until the age of 70 , so both life tables show very similar figures for the remaining life expectancy. Above the age of 70 , the drop in mortality can no longer compensate for the census effect. Hence, due to the dominant census effect, the remaining life expectancy in this age range is lower in the 2010/12 general life table than in the 2009/11 life table. For females, the lesser census adjustments ensure that remaining life expectancy until age 87 is higher based on the census data in the period 2010/12 than in the 2009/11 life table. Only above this age does the census effect dominate the mortality effect among women, hence the remaining life expectancy in the life table based on the census results is shorter than in the previous 2009/11 life table.

When considering these effects, we must take into account that remaining life expectancy is a cumulative measure for mortality conditions above the respective age. The effects in the absolute consideration are in part the greatest at younger years of age because all of the influences of the older age groups are taken together. Even if the census caused relatively extensive revisions of the population figures above age 90, they only affect the values of remaining life expectancy in a marginal way. Not only is remaining life expectancy in this age range already very short, but the extrapolation method used to calculate life tables on the update basis already balanced out most of the updating errors in the population data with regard to the calculation of probability of death in this age range.

\subsection{Effects of the census on the measurement of mortality according to nationality}

\subsubsection{Mortality conditions of the German population}

Compared to the total population, the census adjustments to the population figures were less than average for the German population - the population of German men was revised by 1.0 percent $(-374,398)$ and that of German women only by 0.2 percent (-74,085) (Kaus/Mundil-Schwarz 2015: 30). The largest revisions can be identified among advanced ages. The number of German men aged 95 years or older was revised downwards by the census by 64.2 percent $(-31,603)$ and that of German women in this age range by 17.4 percent $(-19,689) .^{2}$

Figure 2 shows the age-specific probability of death that was calculated with the population figures of the old population updates and with the data from the 2011 census. If we look at the pattern of the probability of death based on the old population updates it is clear that they are plausible only until about age 90 . Above age 90 the probability of death of men and women overlap in a mortality crossover or the patterns begin to drop in an implausible way. In this kind of situation it is common to employ an extrapolation method to generate plausible patterns (Eisenmenger

2 Calculation on the basis of the population updates of 31.12.2011 based on earlier censuses and on the 2011 census. 
Fig. 2: Age-specific probability of death 2010/12 among the German population based on the old population updates (incl. extrapolation) and based on the 2011 census

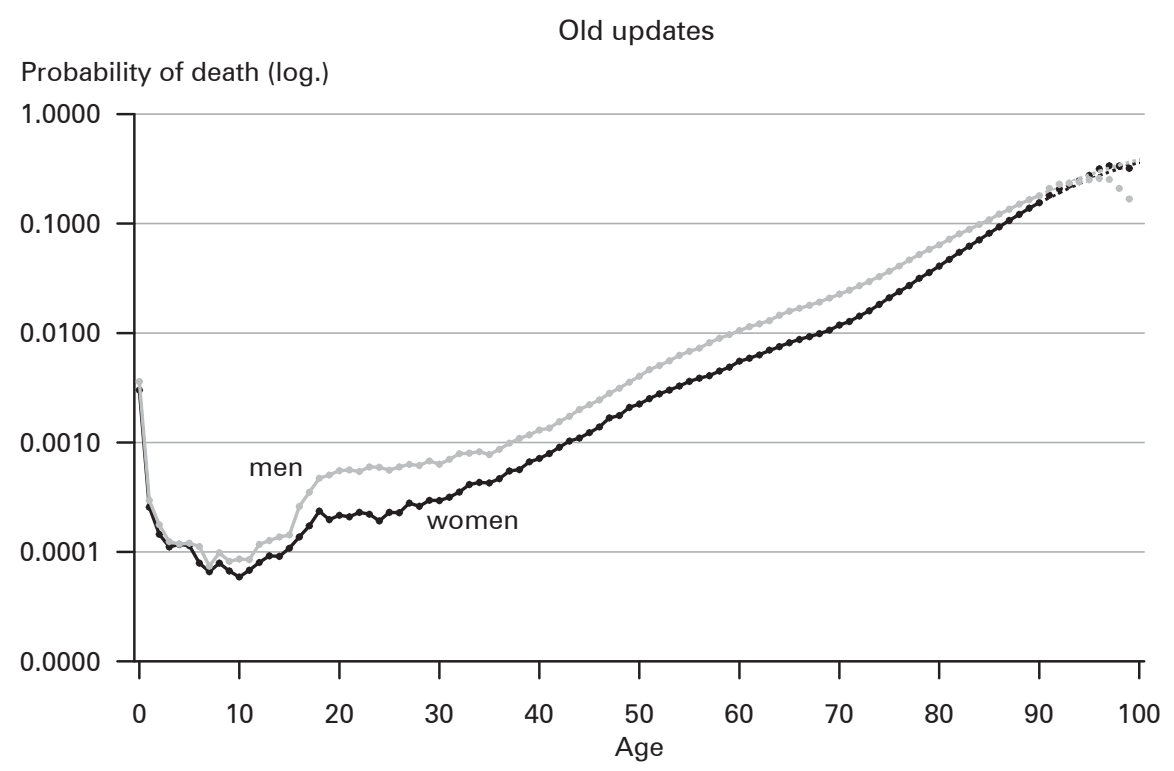

Census

Probability of death (log.)

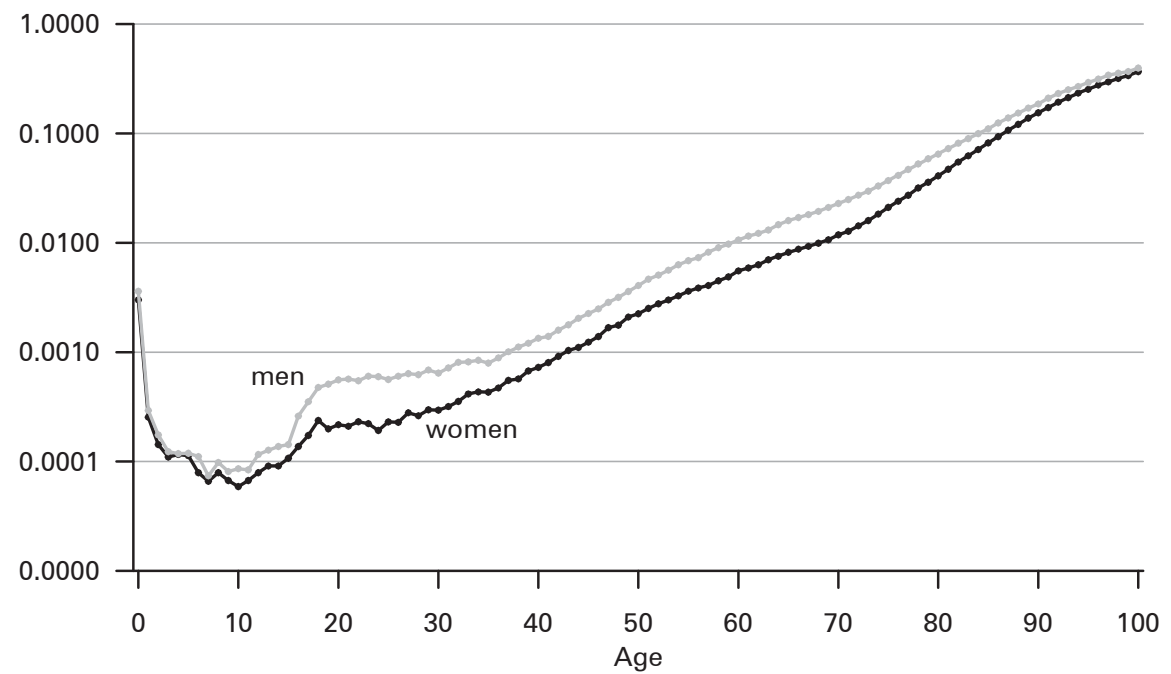

Source: Federal Statistical Office, own calculations and design

2003; Statistisches Bundesamt 2015a). The extrapolated figures are portrayed in Figure 2 as a dashed line and the unused observed figures of the probability of death as unconnected data points. The use of the extrapolated figures had no effect 
on the measured life expectancy at birth. For German men, the figure for e(0) with and without extrapolation is 77.7 years and for women 82.7 years (see Table 1).

Tab. 1: Life expectancy at birth of the German population 2010/12 based on different calculations

\begin{tabular}{lcc}
\hline & Men & Women \\
\hline Old population updates & 77.7 & 82.7 \\
Old population updates inclusive extrapolation & 77.7 & 82.7 \\
Census & 77.6 & 82.7 \\
Census inclusive extrapolation and smoothing & 77.6 & 82.7 \\
\hline
\end{tabular}

Source: Federal Statistical Office, own calculations

Fig. 3: Age-specific probability of death 2010/12 in the German population based on the 2011 census: observed and adjusted figures

Probability of death (log.)

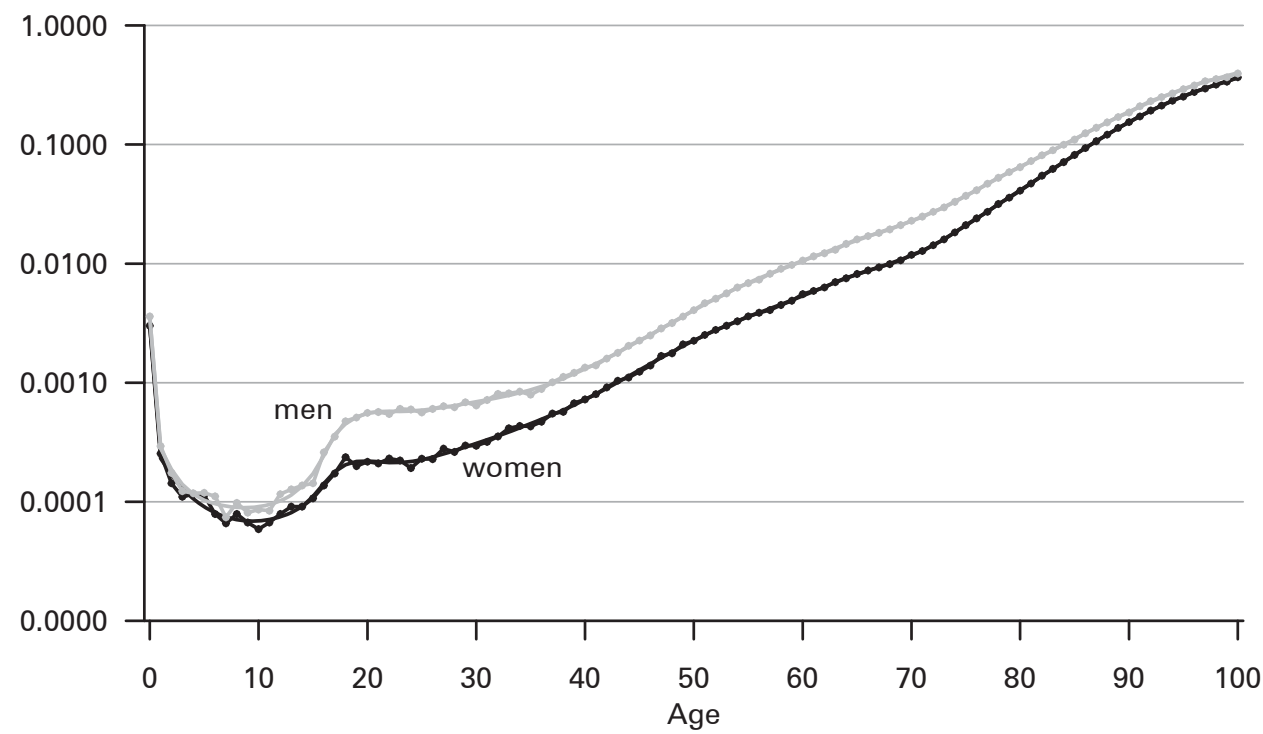

Source: Federal Statistical Office, own calculations and design

When the life tables for the German population are calculated based on the 2011 census, then the life expectancy at birth for men is 0.1 years shorter than when based on the old updates (new figure: 77.6 years), for women the measured figure of 82.7 years remains the same even when based on the census, in spite of the minor revisions to the population figures. It is striking that the census-based probability of 
death until age 100 now results in plausible figures so that the use of an extrapolation method is no longer necessary up to this age. ${ }^{3}$

The next step involved smoothing the census-based probabilities of death for the German population in order to generate a mortality pattern over age not influenced by random effects (see Fig. 3). Due to the high number of cases among the German population, the influence of the smoothing method is very low. The most notable difference is that the probability of death of men and women now no longer cross over as they did in the observed pattern at the ages of 4 and 5 . The influence of the smoothing method is visible on a logarithmic scale until about age 35; above that age the observed and adjusted figures are practically identical.

The pattern of the adjusted probability of death for the German population and the life table based on these figures is used in the following to analyze the fundamental mortality patterns of the German population and compare it with the corresponding results for the foreign population. For example, if we look at the pattern of the age-specific (remaining) life expectancy based on these figures compared to figures based on the old updates it becomes particularly clear how minor the cen-

Fig. 4: Differences in the age-specific life expectancy between a 2010/12 life table for the German population based on old population updates and the 2011 census (census effect)

$\mathrm{e}(\mathrm{x})$ differences in years

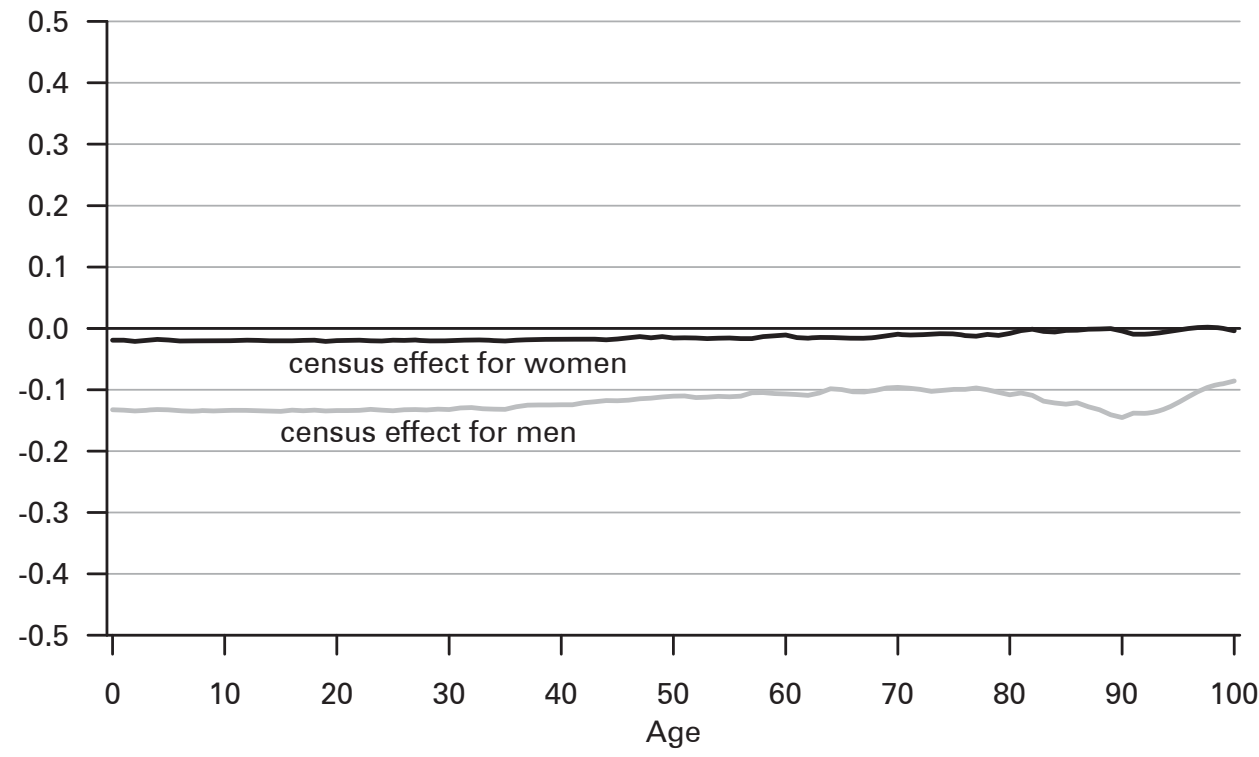

Source: Federal Statistical Office, own calculations and design

3 To calculate a complete life table until the age of 112, an extrapolation method was nevertheless used, as it was used for the compilation of the 2010/12 general life table over age 100. Probabilities of death only marginally influence the figures for life expectancy above the age of 100 . 
sus revisions are with regard to measuring the mortality of the German population. The remaining life expectancy of German women is influenced only marginally so that even the first decimal in each year of age based on the census and based on the old updates is identical. For males the remaining life expectancy on the census basis is revised downwards over the entire age course by 0.1 years.

\subsubsection{Mortality conditions of the foreign population}

The census adjustments were particularly pronounced for the foreign population. The male population was revised downwards by 15.9 percent $(-602,318)$ and the female by 12.9 percent $(-465,042)$ (Kaus/Mundil-Schwarz 2015: 30). The greatest revisions at an advanced age were also for the foreign population. Above the age of 75, the census reduced the populations by 36.2 percent $(-46,008 \mathrm{men})$ and 38.9 percent $(-51,242$ women). Above the age of 95 the revisions were 94.5 percent for males and 90.6 percent for females. The census-adjusted intercensal population updates for this age group registered only 1,831 persons (547 men and 1,284 women) on 31.12.2011 rather than 23,561 persons, as had been indicated by previous updates.

Figure 5 shows the age-specific probability of death of the foreign population based on the old updates and based on the 2011 census. It is notable that based on the old population updates the pattern of the age-specific probabilities of death is already implausible from age 75: The probability of death among males rises to a lower level than the previous age groups would suggest, making a crossover of the male and female probability of death occur at the age of 84 . Using the extrapolation methods (dashed line), however, we can generate a plausible continuation of the pattern above age 75 . Since with this method observed figures are replaced by (higher) figures from the extrapolation model far earlier in the age course compared to the German population, the influence on the measured (remaining) life expectancy is accordingly greater. Based on the observed figures, we would ascertain life expectancy at birth of foreign men of 84.8 years and 88.3 years for women. Using the extrapolation method considerably reduces these figures to 82.9 years for the newborn males ( -1.9 years) and 87.8 years for the females ( -0.5 years).

Based on the 2011 census, we derive more plausible probabilities of death to far higher age groups than based on the old population updates. The census-adjusted life expectancy of foreign men calculated with the observed data is 80.9 years and of women it is 85.0 years. In spite of the greater revisions among the male population figures, the census adjustment is greater for females (-2.8 years) than males (-2.0 years). This is only because the extrapolation based on the updates had a far stronger effect for the men than for the women. A comparison of these figures is nevertheless advisable since the use of the extrapolation methods based on the old updates would have been urgently necessary to draw up an intrinsically plausible life table for the foreign population.

In order to derive a characteristic mortality pattern for the foreign population, even when based on the census, not only is the use of a smoothing method, but also of an extrapolation method necessary before age 100. Figure 6 illustrates this pattern and compares it to the observed figures. The unused observed figures are, 
Fig. 5: Age-specific probability of death 2010/12 for the non-German population based on the old population updates (incl. extrapolation) and based on the 2011 census

Old updates

Probability of death (log.)

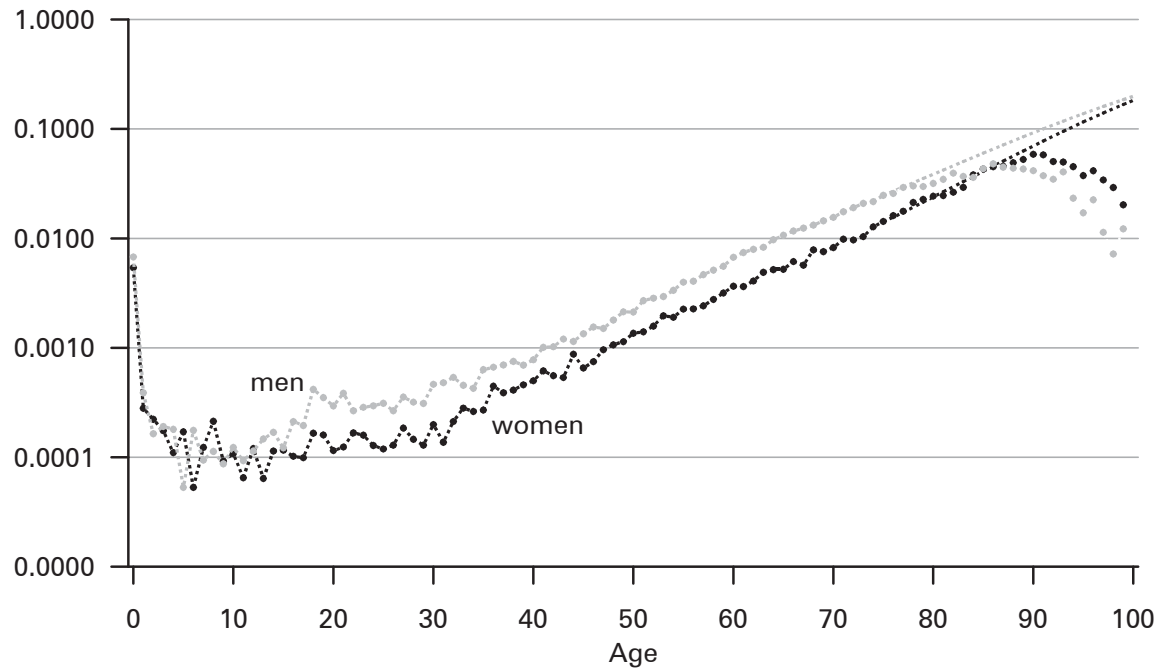

Census

Probability of death (log.)

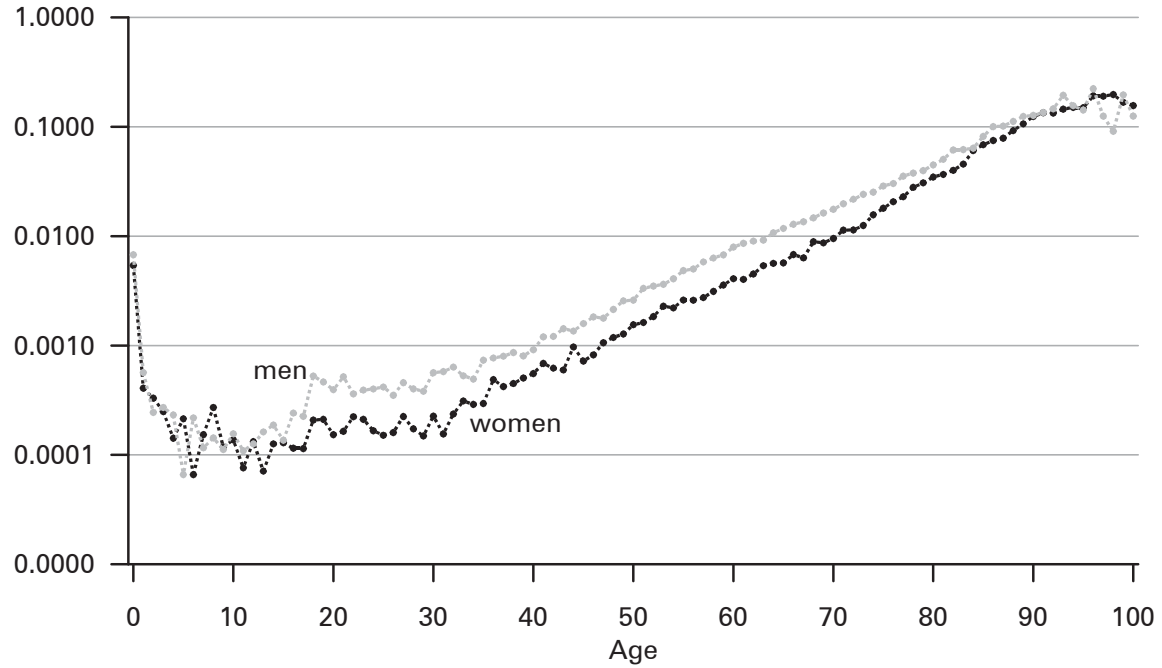

Source: Federal Statistical Office, own calculations and design

as in the above figures, shown as single data points, while the figures included in the smoothing method are connected. The smoothed pattern is shown as a solid line and the extrapolated figures as a dashed line. Based on the census the smoothed 
Fig. 6: Age-specific probability of death 2010/12 of the non-German population based on the 2011 census: observed and adjusted figures

Probability of death (log.)

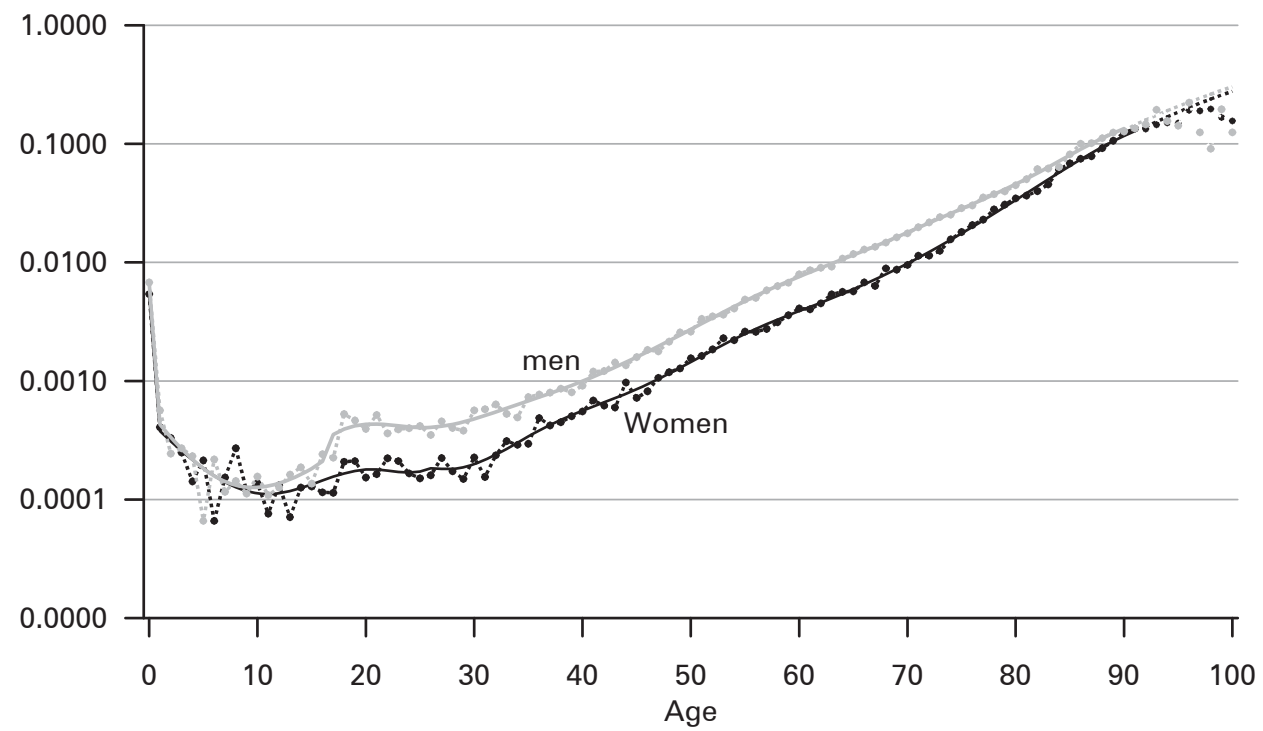

Source: Federal Statistical Office, own calculations and design

patterns were replaced by extrapolated figures for males from age 91 and for females from age 92 . The probability of death based on these methodological interventions result in a life expectancy at birth of 80.5 years for foreign men and 84.8 years for foreign women, and the figures are therefore again somewhat lower than those based on the observed data (see Table 2).

Tab. 2: Life expectancy at birth of the non-German population 2010/12 based on different calculations

\begin{tabular}{lcc}
\hline & Men & Women \\
\hline Old updates & 84.8 & 88.3 \\
Old updates inclusive extrapolation & 82.9 & 87.8 \\
Census & 80.9 & 85.0 \\
Census inclusive extrapolation and smoothing & 80.5 & 84.8 \\
\hline
\end{tabular}

Source: Federal Statistical Office, own calculations

If we use the smoothed patterns of the age-specific probabilities of death shown in Figure 6 to calculate a complete life table and then compare these figures with those from the old intercensal population updates, we can establish a census effect of 2.4 years for males and 3.0 years for females for life expectancy at birth. Figure 7 shows the pattern of the census effects for the (remaining) life expectancy over 
Fig. 7: Differences in the age-specific life expectancy between a 2010/12 life table for the non-German population based on updates and the 2011 census (census effect)

$\mathrm{e}(\mathrm{x})$ differences in years

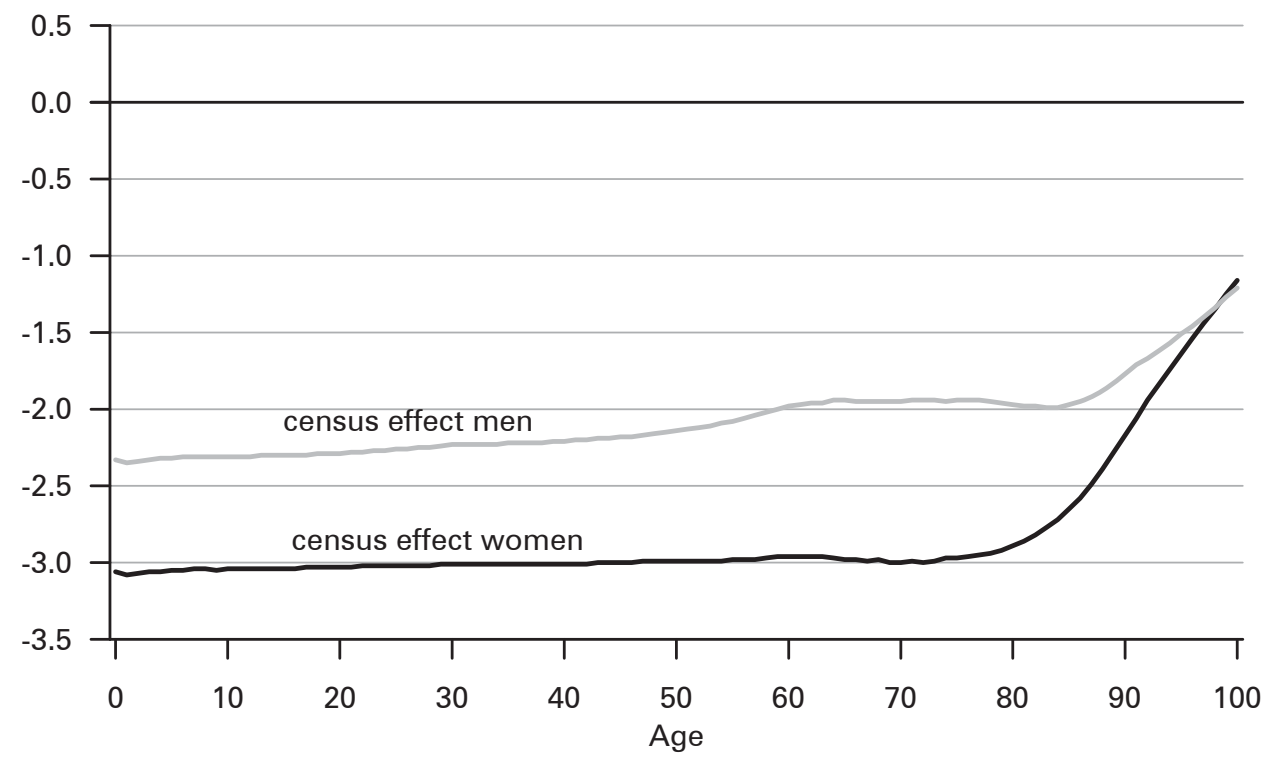

Source: Federal Statistical Office, own calculations and design

the entire age range. For males, the figures for the $\mathrm{e}(\mathrm{x})$-difference induced by the census up until age 85 are only slightly reduced - at this age the census effect is still 2 years, but the influence of the census declines distinctly in the following years of age. Even the remaining life expectancy at age 100 is, despite of the use of an extrapolation method for the data from the old population updates, reduced by another 1.2 years if the data from the census are used as the basis for the calculation. For females the influence of the census of 3 years on the remaining life expectancy remains nearly constant beyond the age of 70 before it also drops to a figure of 1.2 years at age 100.

\subsubsection{Comparison of the mortality conditions of Germans and non- Germans}

In the previous sections, we presented characteristic patterns for the age-specific probabilities of death of Germans and foreigners based on the data from the 2011 census by using methodological interventions such as smoothing and extrapolating. In Figure 8, these patterns are illustrated broken down by sex. The solid lines are the smoothed patterns. Figures modelled for the foreign population using the extrapolation method are displayed with dashed lines. 
Fig. 8: Age-specific probability of death 2010/12 for German and non-German population

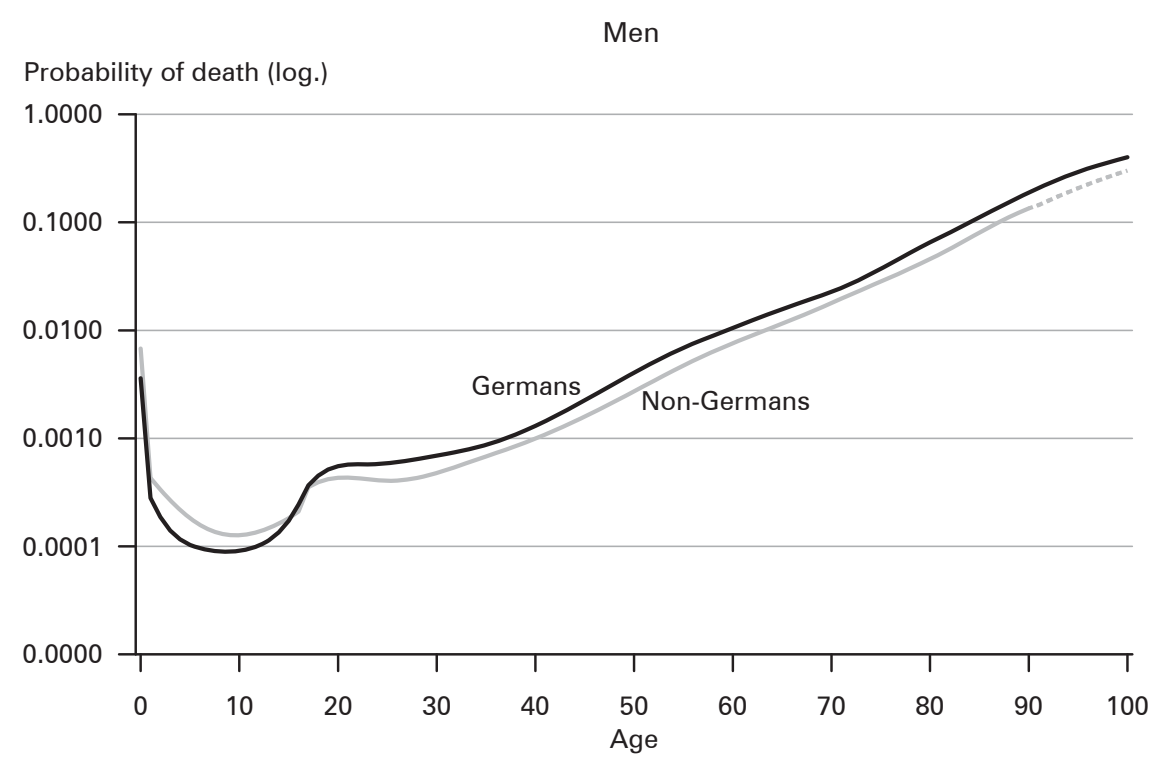

Women

Probability of death (log.)

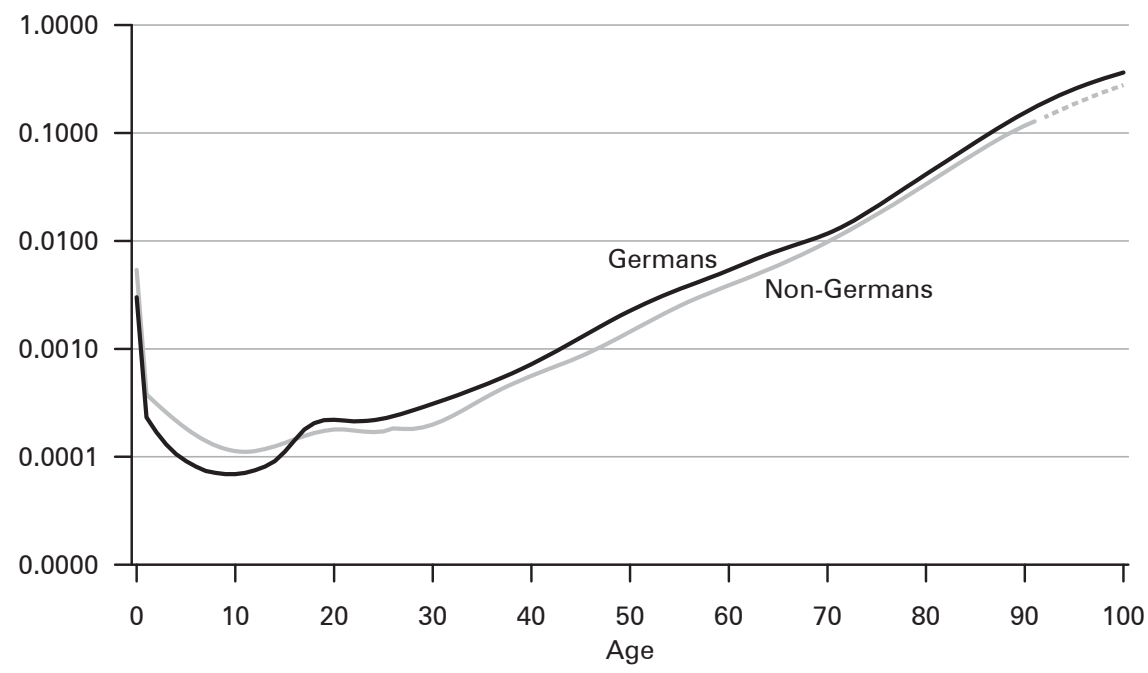

Source: Federal Statistical Office, own calculations and design

A look at the respective patterns reveals that the mortality conditions differ among the German and non-German population for men and women in a very similar way. For infants, during childhood and early adolescence, persons with foreign nationalities exhibit a higher probability of death than persons of the same ages of 
German nationality. For boys the ratio reverses at the age of 16 and for girls at 17. In all ensuing years of age, foreign men and women always exhibit a lower probability of death than Germans of the same ages. If we calculate confidence intervals for the patterns of the probability of death they show that the differences for newborn boys and girls are significant, but not for the following years of childhood and youth. Because of the low numbers of cases among the foreign population the confidence intervals in this age range are correspondingly broad, implying no significant differences with a 5 percent probability of error.

Significant differences in the probability of death of Germans and non-Germans are found among males between the ages of 25 and 32 and above age 38. For females the differences are significant at age 31 and all years of age over 41 . No confidence intervals can be calculated in the same manner for the extrapolated figures, and therefore no comparable statements can be made about the significance of the differences above age 91 for males and 92 for females. The extrapolated figures for the male and female foreign population are, however, outside the confidence interval of the probability of death calculated for the German population, indicating significant differences.

Figure 9 additionally portrays the mortality differences between Germans and non-Germans in percent (measured value $U_{x}$ ). The figure shows, for example, that infant mortality of children born with foreign nationalities is about 80 to 90 percent higher than that of German children. In ensuing years of age the differences are not significant, even in the three-year period under review, due to the low cases of deaths and should therefore not be overinterpreted.

Basically, the patterns do fit in with earlier findings according to which foreign children had an increased mortality compared to the German population until adolescence. Above age 25, however, the differences are mostly significant and fluctuate between a 20 and 35 percent lower probability of death among foreigners compared to Germans.

Based on the census data we cannot recognize a clear pattern as indicated by earlier studies whereby the differences are particularly strong at working age and then decrease at later ages or even reverse into a higher mortality level of the foreign population. No such tendency can be identified for males, and for females only to a very small extent, since the mortality differences between age 65 and 72 drop a great deal but then rise again in the ensuing years of age.

The difference between Germans' and non-Germans' life expectancy at birth is 2.9 years for males and 2.1 years for females in the census-based data adjusted for random influences. At age 17, the age from which the foreign population consistently exhibits a lower probability of death among men and women, the differences in remaining life expectancy are even 3.3 years for males and 2.3 years for females. Even at the age of 65 we ascertain considerable differences: the remaining life expectancy of foreign men is 2.4 years higher and that of women 1.7 years higher compared to German persons of the same ages (cf. Table 3). 
Fig. 9: Age-specific differences between the probability of death of the German and the non-German population based on the census for the period 2010/12

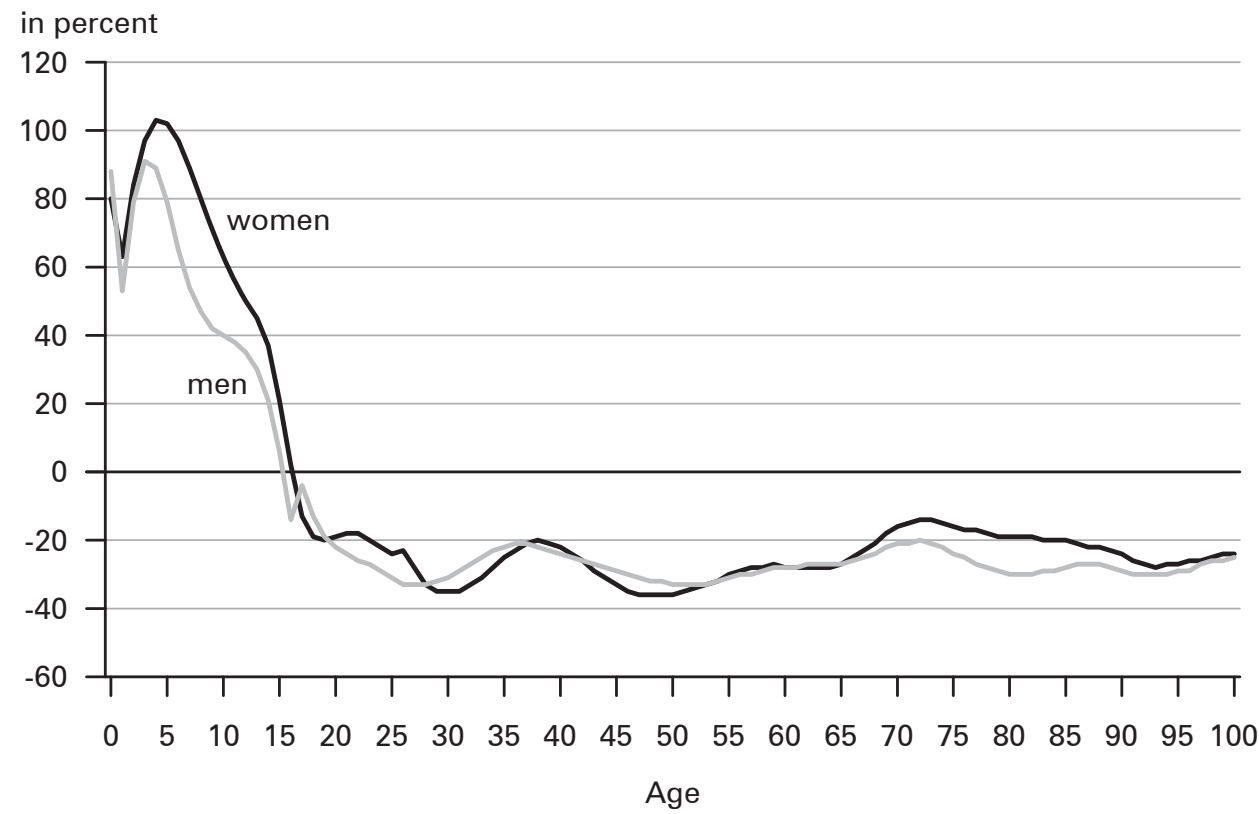

Source: Federal Statistical Office, own calculations and design

Tab. 3: $\quad$ Remaining life expectancy in selected age groups for the German and non-German population 2010/12 (based on the 2011 census - life tables with adjusted probability of death and extrapolated figures at advanced age)

\begin{tabular}{lcccc}
\hline \multirow{2}{*}{$\begin{array}{l}\text { Remaining life expectancy } \\
\text { at the age of ... }\end{array}$} & Germans & Non-Germans & Germans & Non-Germans \\
\hline 0 years & 77.6 & 80.5 & 82.7 & 84.8 \\
20 years & 58.1 & 61.4 & 63.1 & 65.5 \\
40 years & 38.8 & 41.9 & 43.5 & 45.8 \\
65 years & 17.4 & 19.8 & 20.7 & 22.4 \\
80 years & 7.7 & 9.5 & 9.2 & 10.6 \\
\hline
\end{tabular}

Source: Federal Statistical Office, own calculations 


\section{Discussion}

Data from the 2011 census have made it possible to analyze basic mortality patterns in Germany. The great advantage of the census data is that the population figures were surveyed as exactly as possible and they are free of population updating or back-calculation errors. An updating error in the population data was regarded as the main reason that the life expectancy of the foreign population in particular was cited as too high. The results of the 2010/12 general life table already showed for the entire population of Germany that based on the census, life expectancy is somewhat lower than on the basis of the old updates. For men, the figure for life expectancy at birth on the basis of the census was exactly the same as in the latest life table produced on the basis of the old updates for the period 2009/11. These analyses showed that the census effect on the life expectancy of newborn boys was just as great as the decline in mortality between the two observation periods; therefore the figures correspond exactly. Due to the less pronounced census-based revisions of population figures among women, who had a similar sized decline in mortality between 2009/11 and 2010/12, the life expectancy of newborn girls in the comparison of both mortality tables rose slightly (+0.1 years). Not until old age is the remaining life expectancy based on the census slightly lower among both sexes as a result of the large (relative) population adjustments in this age range compared to the last life table, which was calculated based on the old updates (2009/11). At the total population level, the impact of the census was consequently relatively low and provides no evidence for a need to reassess the general view on mortality in Germany. The figures were revised by approximately the amount of currently observable mortality changes between two calculation periods.

A differentiated consideration by nationality, which is subject to the addressed methodological restrictions, shows more distinct effects on the level of life expectancy measured by the census. The life expectancy of the female German population was practically not influenced, and that of the male population is 0.1 years lower than when measured on the basis of the old population updates. The revisions for the foreign population were correspondingly greater. The life expectancy at birth of foreign men is 2.4 years lower and that of foreign women 3.0 years lower than figures that would have been determined for the same period under consideration on the basis of the old population update data. In this comparison, the influence of an extrapolation method must be considered, because its use had already resulted in significant downward corrections of the life expectancy of the foreign population on the basis of the old population updates - but more for men than for women. The previously extrapolated figures at an advanced age nonetheless underestimated the reliably determinable probability of death ascertained on the basis of the census. The reason for this is that due to the census, the base values of the extrapolation for the probability of death also had to be revised upwards. Based on the census, a plausible probability of death of the foreign population can be identified up to significantly higher years of age, so that the necessary extrapolation above age 91 (men) and 92 (women) has recourse to reliable reference values and results in generally more plausible mortality patterns. These results show how great the 
influence of the extrapolation method in the preparation of life tables for subpopulations can be. In comparable studies it is therefore elementary to disclose and justify the background information for the extrapolation such as the starting age and the method used.

If we compare the characteristic mortality patterns of the German and the foreign populations over the entire age range, there is no fundamentally new result based on the census, but there are significantly reduced differences compared to analyses based on the old population updates. The advantage of the foreign population in the level of life expectancy at birth drops from 5.2 years to 2.9 years for men and from 5.1 years to 2.1 years for women. Also above age 65 , there is a clear and largely significant mortality advantage among the foreign population. The relative differences in the age-specific probability of death differ little at advanced ages from those of working age people. The findings point towards a strong selection effect (healthy migrant effect). Evidence of an adaptation effect that would ensure a strong alignment of mortality levels between the German and the foreign population at more advanced ages cannot be found with the census-based results. However, additional selection effects, for example during naturalisation or selective emigration, may play a role. With increasing age, the percentage of naturalised persons among the originally foreign population also rises; however, in recent decades naturalisation behaviours have not been uniform, making it difficult to assess this process. It is also possible that people of non-German nationality and increased morbidity tend to migrate back to their country of origin. Therefore based on this analysis we cannot rule out an adaptation effect at the individual level, even if it cannot be proven at the macro level. A significantly higher probability of death among non-Germans can only be demonstrated for infants in both sexes. However, the results also indicate a higher probability of death in childhood and early adolescence among the foreign population, although the differences in this age range are not significant. Overall, the results confirm that the foreign population, despite given socio-economic disadvantages ${ }^{4}$ has a significantly lower mortality than the German population. This constellation can be described as a paradox, since in numerous studies socio-economic disadvantages are associated with higher mortality. ${ }^{5}$

The results presented do not paint an entirely new picture of mortality conditions in Germany. Looking at the total population, incorporating the population figures from the 2011 census has only minor effects on the measured life expectancy. However, it discloses interesting findings with regard to the mortality of the foreign population and differences between it and the mortality of the population with German nationality. The data from the 2011 census enable us to indeed detect a healthy migrant effect and thus a lower mortality of the foreign population - albeit to a much lesser extent than on the basis of the old population updates - even when errors

4 For a detailed description of the socio-economic situation of the foreign population in Germany, cf. for example the 10. Bericht der Beauftragten der Bundesregierung für Migration, Flüchtlinge und Integration über die Lage der Ausländerinnen und Ausländer in Deutschland (2014). For a detailed compilation of relevant studies, cf. for example Hoffmann (2008), Chapter 4. 
in the intercensal population updates are excluded. Previously, a disproportionate underreporting of the foreign population in the intercensal population updates had been cited as one of the main reasons for the significantly longer life expectancy of the foreign population on the basis of these data (Luy 2007; Kibele et al. 2008; Koh/s 2008a/b, 2011, 2012; Mammey/Schwarz 2002; Robert Koch Institut/Statistisches Bundesamt 2008).

To estimate the importance of the healthy migrant effect, in the past researchers therefore resorted to alternative data sources (e.g. the Central Register of Foreign Nationals, the GRV data or the Integration Survey). These studies, however, were subjected to other restrictions, as they do not have recourse to a survey of the entire population and of deaths to analyze mortality differences between the German and the foreign population (see section 4.1). Based on the census, the findings presented here on the mortality of German and foreign population now permit us - with the largest possible certainty - to rule out that the healthy-migrant effect of previous findings was merely an artefact. Future research reflecting this outcome can again deal more with substantive explanations for the documented mortality differences between the German and the foreign population. The life tables for the German and non-German population made available in the online appendix, for example, allow us to go into age-specific differences in more detail.

\section{Acknowledgements}

We would like to thank Olga Pötzsch, Michael Mühlichen and two anonymous reviewers for important advice on earlier versions of this article.

\section{References}

Balducci, Gaetano 1917: Costruzione e critica delle tavole di mortalità. In: Giornale degli Economisti e Rivista di Statistica, Serie terza, 55: 455-484.

Becker, Karl 1874: Zur Berechnung von Sterbetafeln an die Bevölkerungsstatistik zu stellende Anforderungen. Berlin.

Die Beauftragte der Bundesregierung für Migration, Flüchtlinge und Integration (Ed.) 2014: 10. Bericht der Beauftragten der Bundesregierung für Migration, Flüchtlinge und Integration über die Lage der Ausländerinnen und Ausländer in Deutschland [http:// www.bundesregierung.de/Content/Infomaterial/BPA/IB/10_Auslaenderbericht_2015. pdf, 08.06.2016].

Eilers, Paul H.C.; Marx, Brian D. 1996: Flexible Smoothing with B-splines and Penalties. In: Statistical Science 11,2: 89-121.

Eisenmenger, Matthias 2003: Die Erweiterung der abgekürzten Sterbetafel in den Altersstufen von 90 bis 100 Jahre. In: Sonderausgabe Wirtschaft und Statistik, ISI-Weltkongress: 90-92.

Eurostat 2015: Online-Datenbank - Tabelle Todesursachen - absolute Zahl im Berichtsland und für Einwohner (hlth_cd_aro) [http://appsso.eurostat.ec.europa.eu/nui/show. do?dataset=hlth_cd_aro, 08.0̄6. 2016$]$. 
Fleischer, Henning 1989: Entwicklung der Ausländerzahl seit 1987. In: Wirtschaft und Statistik 9: 594-599.

Hoffmann, Rassmus 2008: Socioeconomic Differences in Old Age Mortality. In: Land, Kenneth $C$. (Ed.): The Springer series on demographic methods and population analysis 25. Springer, Dordrecht [doi: 10.1007/978-1-4020-8692-2].

Kaus, Wolfhard; Mundil-Schwarz, Rabea 2015: Die Ermittlung der Einwohnerzahlen und der demografischen Strukturen nach dem Zensus 2011. In: Wirtschaft und Statistik 4: 18-38.

Kennedy, Steven; Kidd, Michael P. 2015: The Healthy Immigrant Effect: Patterns and Evidence from Four Countries. In: Journal of International Migration and Integration 16,2: 317-332 [doi: 10.1007/s12134-014-0340-x].

Kibele, Eva; Scholz, Rembrandt; Shkolnikov, Vladimir M. 2008: Low migrant mortality in Germany for men aged 65 and older: fact or artifact? In: European Journal of Epidemiology 23: 289-393 [doi: 10.1007/s10654-008-9247-1].

Koh/s, Martin 2008a: Einfluss von Auswahlprozessen auf die Sterblichkeit verschiedener Zuwanderergruppen in Deutschland. In: DRV-Schriften 55: 153-175.

Koh/s, Martin 2008b: Leben Migranten wirklich länger? Eine empirische Analyse der Mortalität von Migranten in Deutschland. Bundesamt für Migration und Flüchtlinge, Working Paper 16.

Koh/s, Martin 2008c: Healthy-Migrant-Effect, Erfassungsfehler und andere Schwierigkeiten bei der Analyse der Mortalität von Migranten - Eine Bestandsaufnahme. Bundesamt für Migration und Flüchtlinge, Working Paper 15.

Koh/s, Martin 2011: Morbidität und Mortalität von Migranten in Deutschland. Bundesamt für Migration und Flüchtlinge, Forschungsbericht 9.

Koh/s, Martin 2012: Demographie von Migranten in Deutschland. In: Razum, Oliver (Ed.): Challenges of public health 63. Frankfurt a.M.: Peter Lang.

Koh/s, Martin 2015: Sterberisiken von Migranten - Analysen zum Healthy-Migrant-Effekt nach dem Zensus 2011. In: Bundesgesundheitsblatt 58/6: 519-526 [doi: 10.1007/ s00103-015-2140-7].

Luy, Marc 2007: Estimating the Migrant Survival Advantage from Orphanhood of Second Generation Migrants. Rostocker Zentrum zur Erforschung des demografischen Wandels, Rostocker Zentrum Diskussionspapier 17.

Mammey, Ulrich; Schwarz, Karl 2002: The demographic characteristics of the immigrant population in Germany. In: Haug, Werner; Compton, Paul; Courbage, Youssef (Eds.): The demographic characteristics of immigrant populations. Population Studies 38. Strassburg: Council of Europe: 193-244.

Moullan, Yasser; Jusot, Florence 2014: Why is the 'healthy immigrant effect' different between European countries? In: European Journal of Public Health 24,1: 80-86 [doi: 10.1093/eurpub/cku112].

Nielsen, Signe Smith; Krasnik, Allan 2010: Poorer self-perceived health among migrants and ethnic minorities versus the majority population in Europe: a systematic review. In: International Journal of Public Health 55,5: 357-371 [doi: 10.1007/s00038-010-0145-4].

Opfermann, Heike; Grobecker, Claire; Krack-Roberg, Elle 2006: Auswirkung der Bereinigung des Ausländerzentralregisters auf die amtliche Ausländerstatistik. In: Wirtschaft und Statistik 5: 480-494.

Perks, Wilfred 1932: On some experiments the graduation of mortality statistics. In: Journal of the Institute of Actuaries 63: 12-40. 
Razum, Oliver 2009: Migration, Mortalität und der Healthy-migrant-Effekt. In: Richter, Matthias; Hurrelmann, Klaus (Eds.): Gesundheitliche Ungleichheit - Grundlagen, Probleme, Perspektiven. 2. aktualisierte Auflage. Wiesbaden: VS-Verlag: 268-282.

Razum, Oliver et al. 1998: Low overall mortality of Turkish residents in Germany persists and extends into a second generation: merely a healthy migrant effect? In: Tropical Medicine and International Health 3,4: 297-303 [doi: 10.1046/j.1365-3156.1998.00233.x].

Robert Koch Institut; Statistisches Bundesamt 2008: Schwerpunktbericht der Gesundheitsberichterstattung des Bundes: Migration und Gesundheit. Robert Koch Institut, Berlin [http://edoc.rki.de/documents/rki_fv/ren4T3cctjHcA/PDF/253bKE5YVJxo_28. pdf, 08.06.2016].

Salzmann, Thomas; Kohls, Martin 2006: Mortalitätsanalyse mit den Daten der Deutschen Rentenversicherung - Methodische Überlegungen zum Stichprobencharakter. In: DRV-Schriften 55: 185-199.

Statistisches Bundesamt 2012: Periodensterbetafeln für Deutschland 2009/2011 [https://www.destatis.de/DE/Publikationen/Thematisch/Bevoelkerung/ Bevoelkerungsbewegung/PeriodensterbetafelnBundeslaender5126204117004.pdf, 08.06.2016].

Statistisches Bundesamt 2013: Bevölkerungsfortschreibung auf Grundlage der Volkszählung 1987 (Westen) bzw. 1990 (Osten) [https://www.destatis.de/DE/Publikationen/ Thematisch/Bevoelkerung/Bevoelkerungsstand/Bevoelkerungsfortschreibung.html, 08.06.2016].

Statistisches Bundesamt 2015a: Allgemeine Sterbetafel 2010/12 - Methodische Erläuterungen und Ergebnisse [https://www.destatis.de/DE/Publikationen/Thematisch/Bevoelkerung/Bevoelkerungsbewegung/SterbetafelnAllgemeinErlaeuterung5126205129004.pdf, 08.06.2016].

Statistisches Bundesamt 2015b: Einbürgerungen - Fachserie 1 Reihe 2.1 - 2014 [https:// www.destatis.de/DE/Publikationen/Thematisch/Bevoelkerung/MigrationIntegration/ Einbuergerungen.html, 08.06.2016].

Statistisches Bundesamt 2015c: Ausgangsdaten der Bevölkerungsfortschreibung aus dem Zensus [https://www.destatis.de/DE/Publikationen/Thematisch/Bevoelkerung/ Bevoelkerungsstand/DatenBevoelkerungsfortschreibungZensus.html, 08.06.2016].

Thatcher, A. Roger; Kannisto, Väinö; Vaupel, James W. 1998: The force of mortality at ages 80 to 120, Monographs on Population Aging, 5. Odense: Odense University Press.

Weber, Ingbert et al. 1990: Zur gesundheitlichen Lage der ausländischen Bevölkerung in der Bundesrepublik Deutschland: Erste Erkenntnisse. In: Projektgruppe Prioritäre Gesundheitsziele beim Zentralinstitut für die kassenärztliche Versorgung. Dringliche Gesundheitsprobleme in der Bundesrepublik Deutschland - Zahlen - Fakten - Perspektiven. Baden-Baden: Nomos Verlagsgesellschaft: 577-601.

Wittstein, Theodor 1862: Die Mortalität in Gesellschaften mit successiv eintretenden und ausscheidenden Mitgliedern. In: Archiv der Mathematik und Physik 39: 67-92.

Zeuner, Gustav 1869: Abhandlungen zur mathematischen Statistik. Leipzig.

zur Nieden, Felix; Rau, Roland; Luy, Marc 2016: Allgemeine Sterbetafel 2010/12 - Neue Ansätze zur Glättung und Extrapolation der Sterbewahrscheinlichkeiten. In: Wirtschaft und Statistik 1: 63-73. 
Felix zur Nieden $(\triangle)$, Bettina Sommer. Federal Statistical Office (Destatis). Wiesbaden, Germany. E-mail: felix.zurnieden@destatis.de, bettina.sommer@destatis.de URL: https://www.destatis.de/EN/Homepage.html 


\section{Comparative Population Studies}

WWW.comparativepopulationstudies.de

ISSN: 1869-8980 (Print) - 1869-8999 (Internet)

Published by

Prof. Dr. Norbert F. Schneider

Federal Institute for Population Research

D-65180 Wiesbaden / Germany

\section{(cc) BY-SA}

2016

\section{Managing Editor}

Frank Swiaczny

\section{Assistant Managing Editor}

Katrin Schiefer

\section{Copy Editor}

(Selected Articles in German)

Dr. Evelyn Grünheid

\section{Layout}

Beatriz Feiler-Fuchs

E-mail:cpos@bib.bund.de

\section{Scientific Advisory Board}

Paul Gans (Mannheim)

Karsten Hank (Köln)

Johannes Huinink (Bremen)

Michaela Kreyenfeld (Rostock)

Marc Luy (Wien)

Notburga Ott (Bochum)

Peter Preisendörfer (Mainz)

Nikola Sander (Groningen)

Zsolt Spéder (Budapest)

\section{Board of Reviewers}

Martin Abraham (Erlangen)

Laura Bernardi (Lausanne)

Hansjörg Bucher (Bonn)

Claudia Diehl (Konstanz)

Andreas Diekmann (Zürich)

Gabriele Doblhammer-Reiter (Rostock)

Jürgen Dorbritz (Wiesbaden)

Anette Eva Fasang (Berlin)

E.-Jürgen Flöthmann (Bielefeld)

Alexia Fürnkranz-Prskawetz (Wien)

Beat Fux (Salzburg)

Joshua Goldstein (Berkeley)

Sonja Haug (Regensburg)

Hill Kulu (Liverpool)

Aart C. Liefbroer (Den Haag)

Kurt Lüscher (Konstanz)

Emma Lundholm (Umeå)

Nadja Milewski (Rostock)

Dimiter Philipov (Wien)

Roland Rau (Rostock)

Tomáš Sobotka (Wien) Jeroen Spijker (Barcelona)

Olivier Thévenon (Paris)

Helga de Valk (Brussel)

Heike Trappe (Rostock)

Michael Wagner (Köln) 